\title{
Temperature and solid properties effects on gas-liquid mass transfer
}

\author{
A. Ferreira ${ }^{a, b}$, C. Ferreira ${ }^{b}$, J.A. Teixeira ${ }^{a}$, F. Rocha ${ }^{b, *}$ \\ a IBB-Institute for Biotechnology and Bioengineering, Centre of Biological Engineering, Universidade do Minho, Campus de Gualtar, 4710-057 Braga, Portugal \\ ${ }^{\mathrm{b}}$ LEPAE-Laboratory for Process, Environmental and Energy Engineering, Departamento de Engenharia Química, Faculdade de Engenharia, \\ Universidade do Porto, Rua Dr. Roberto Frias s/n, 4200-465 Porto, Portugal
}

\section{A R T I C L E I N F O}

\section{Article history:}

Received 10 December 2009

Received in revised form 28 May 2010

Accepted 31 May 2010

\section{Keywords:}

Bubble column

Mass transfer

Absorption

Multiphase reactors

Particles

Temperature

\begin{abstract}
A B S T R A C T
The knowledge about the effect of solid phase properties, at different temperatures, on gas-liquid transfer and the respective physical mechanisms has been poorly studied. In the present work, the temperature and solid properties (size and density) effects on the gas-liquid mass transfer characteristics in a bubble column were experimentally evaluated. Gas-liquid-solid systems formed by air/water/polyvinyl chloride (PVC) beads and air/water/expandable polystyrene (EPS) beads were used. For each system, volumetric liquid side mass transfer coefficient, $k_{L} a$, was determined under different temperatures $\left(20-35^{\circ} \mathrm{C}\right)$, superficial gas velocities (up to $7.2 \mathrm{~mm} / \mathrm{s}$ ), solids sizes (210,549 and $591 \mu \mathrm{m}$ ) and concentration (up to 5 vol.\%). The results show that the temperature plays an important role on mass transfer phenomena as $k_{L} a$ increases as temperature is increased. However, temperature does not have, significantly, influence on the solids effect on $k_{L} a$. In what concerns the effect of the solids on $k_{L} a$, a negative effect of their presence is observed being this effect more pronounced for the largest particles (for PVC). In addition, for the same solid size, a decrease in $k_{L} a$ occurs when the solid loading increases (observed in both cases, PVC and EPS). Complementary, bubble/particle interaction studies, using an image analysis technique, were also done aiming a better understanding of the effects of the two types of particles - PVC and EPS - on $k_{L} a$ values, being clearly confirmed that physical (e.g. density) and chemical properties of the solids are important parameters to be taken into account on mass transfer and hydrodynamic studies.

Based on theoretical models for $k_{L}$ and $a$, an empirical correlation for $k_{L} a$ dependence on the experimental variables was developed. The experimental results were fitted with a mean deviation of $5 \%$, that is similar to the experimental error (5\%).
\end{abstract}

(C) 2010 Elsevier B.V. All rights reserved.

\section{Introduction}

Bubble column reactors are intensively utilized as multiphase contactors and reactors in chemical, petrochemical, biochemical and metallurgical industries [1]. This kind of reactors can operate in two and three phase systems, being the last one more complex and highly used at the industry. Three-phase bubble column reactors are widely employed in reaction engineering, i.e. in the presence of a catalyst and in biochemical application where microorganisms are used as solid suspension. The effect of solids on mass transfer process is the most studied subject in this field. However, the knowledge about the effect of solids on gas-liquid systems at different temperatures and the respective physical mechanisms are not yet clarified. A proper understand of the effect of temperature on mass transfer in bubble column is essential to the optimum design and operation of this kind of reactors [2].

\footnotetext{
* Corresponding author. Tel.: +351 225081678; fax: +351225081632

E-mail address: frocha@fe.up.pt (F. Rocha).
}

The presence of solid particles may influence the volumetric mass transfer coefficient $\left(k_{L} a\right)$ by affecting either the individual liquid-side mass transfer coefficient $\left(k_{L}\right)$ or gas-liquid interfacial area $(a)$. These effects can be also changed by temperature variation.

Also, only a limited amount of data are found dealing separately with $k_{L}$ and $a$ in bubble columns, as most of the developed work is limited to the determination of the $k_{L} a$, that, unfortunately, is a global parameter and not sufficient to provide an understanding of the mass transfer mechanisms [3].

The mass transfer from the gas to the liquid is the most important goal of the process in bubble columns reactors. The individual liquid-side mass transfer coefficient can be determined from measurements with single bubbles, whenever the g-l interfacial area and $k_{L} a$ are known. Alternatively, $k_{L}$ values can be estimated from correlations [4].

The solid particles can increase and decrease $k_{L}$, depending on the solids loading, size and their surface properties. The solid particles can increase $k_{L}$ by enhancing turbulence at the gas-liquid interface and inducing surface renewal. By other way, the solid particles can limit the diffusion path, blocking the available area for mass transfer and decrease $k_{L}[5,6]$. $k_{L}$ depends also on other vari- 


\begin{tabular}{|ll|}
\hline Nomenclature \\
$A_{\text {error }}$ & mean deviation \\
$A_{\text {sup }}$ & mean superficial area of the bubbles $\left(\mathrm{m}^{2}\right)$ \\
$a$ & gas-liquid interfacial area $\left(\mathrm{m}^{-1}\right)$ \\
$c$ & oxygen concentration in the liquid $(\mathrm{kg} / \mathrm{L})$ \\
$C_{0}$ & oxygen concentration in the liquid at $t=0(\mathrm{~kg} / \mathrm{L})$ \\
$c^{*}$ & oxygen solubility in the liquid $(\mathrm{kg} / \mathrm{L})$ \\
$D_{L}$ & diffusivity of gas in the liquid $\left(\mathrm{m}^{2} / \mathrm{s}\right)$ \\
$D_{L}^{\prime}$ & liquid dispersion coefficient $\left(\mathrm{m}^{2} / \mathrm{s}\right)$ \\
$D_{T}$ & column diameter $(\mathrm{m})$ \\
$d_{b}$ & bubble average diameter $(\mathrm{m})$ \\
$d_{p}$ & particle diameter $(\mathrm{m})(\mathrm{mm}$ in Eq. $(8))$ \\
$f$ & volumetric concentration of the particles \\
$f$ & correction factor \\
$g$ & acceleration due to gravity $\left(\mathrm{m} / \mathrm{s}^{2}\right)$ \\
$k$ & correlation dimension \\
$k_{L}$ & liquid-side mass transfer coefficient $(\mathrm{m} / \mathrm{s})$ \\
$k_{L} a$ & volumetric liquid side mass transfer coefficient $\left(\mathrm{s}^{-1}\right)$ \\
$M_{e r r o r}$ & maximum deviation \\
$N_{b}$ & number of bubbles \\
$T$ & temperature $\left({ }^{\circ} \mathrm{C}\right)$ \\
$t$ & time $(\mathrm{s})$ \\
$V_{L}$ & the liquid volume $\left(\mathrm{m}^{3}\right)$ \\
$u_{G}$ & superficial gas velocity $(\mathrm{m} / \mathrm{s})$ \\
$\varepsilon_{G}$ & gas holdup \\
$\varepsilon_{S}$ & solid volume fraction \\
$\mu^{*}$ & effective viscosity of the particle-fluid mixture \\
$\mu_{g}$ & (kg/(m s) \\
$\mu_{l}$ & viscosity of gas phase $(\mathrm{kg} /(\mathrm{ms})$ \\
$\rho_{g}$ & giscosity of liquid phase $(\mathrm{kg} /(\mathrm{m} \mathrm{s})$ \\
$\rho_{l}$ & liquid density $\left(\mathrm{kg} / \mathrm{m}^{3}\right)$ \\
$\rho_{s}$ & solid density $\left(\mathrm{kg} / \mathrm{m}^{3}\right)$ \\
& surface tension $(\mathrm{N} / \mathrm{m})$ \\
& \\
\hline
\end{tabular}

ables like diffusivity of gas in the liquid and viscosity and surface tension of the liquid [7].

In bubble column reactors the variation of $k_{L} a$ is primarily due to the variations in the interfacial area, $a$. So, the determination of $a$ is a imperative process for the correct characterization of the mass transfer process.

The experimental determination of $a$ can be done using chemical and physical methods. The chemical techniques are based on a reaction of known kinetics in which the absorption rate is a function of the interfacial g-l area [4,7-12], while the physical methods are based on the measurement of a physical property. The physical techniques are usually divided in non-invasive (photography and image analysis [13], light attenuation, radiography and laser (and phase) Doppler anemometry [14]), and invasive (e.g. optical fibre probes [5,15-17] and the resistive or conductive probes).

A factor that has a strong influence on interfacial area is the presence of solids in the column. The presence of solids has an impact on bubble properties and, by this way, on interfacial area. In some situations, solid particles induce bubble break-up, increasing $a$, in other cases the solids enhance bubble coalescence which results in bigger bubbles and consequently decreases $\mathrm{g}-1$ interfacial areas $[5,18-20]$. This was attributed, in some studies, to an increase in the apparent slurry viscosity with increasing slurry concentration.

The solid particles affect differently $a$ depending on their properties like size and density [21-23]. The concentration of solids has little influence on $a$ for small concentrations, while for higher concentrations the tendency is to decrease $a[7,9,13]$.

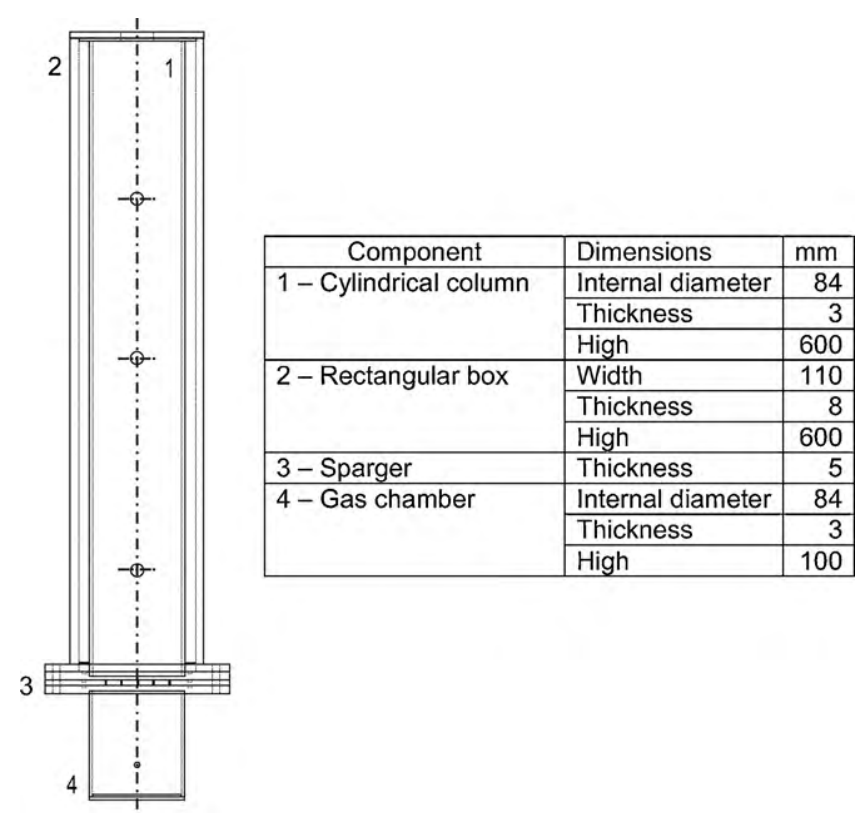

Fig. 1. Bubble column.

The effect of solid particles on $a$ and $k_{L}$ depends on the type of solids and operating conditions. In literature one finds opposite effects for similar conditions, being questionable to preview the effect of a given solid.

Despite all the research efforts, the knowledge about the effects of solids on gas-liquid systems and the respective physical mechanisms have been poorly studied. Even more, most of investigations in bubble column have been performed at ambient conditions in spite of the fact that industrial bubble columns are often operated at increased temperature. In the present work, volumetric mass transfer coefficients, $k_{L} a$, were obtained for different temperatures, gas flow rates and solids size, density and loading. These results were used to develop an empirical correlation, describing the effect of the experimental variables considered on $k_{L} a$. In order to investigate the three phase systems in more detail, bubble/particle interaction was also studied, using an image analysis technique.

\section{Experimental}

\subsection{Experimental set-up}

The contact device used to perform the mass transfer experiments was the bubble column represented in Fig. 1 with the respective dimensions. The device is a perspex cylindrical column covered by a perspex rectangular box to control the temperature through water circulation. At the bottom is located a gas chamber where the gas enters first and then passes through a sparger where the bubbles are formed.

The sparger consists of 13 uniformly spaced needles with an inner diameter of $0.3 \mathrm{~mm}$. The shape and size of the needles ensure the formation of small and well-defined bubbles. It was observed by image analysis that for the range of gas velocity used, the bubble average diameter, $d_{b}$, increases with superficial gas velocity, $u_{G}$, taking the values 3.5 and $5.1 \mathrm{~mm}$ for $u_{G}=2 \mathrm{~mm} / \mathrm{s}$ and $u_{G}=7.2 \mathrm{~mm} / \mathrm{s}$, respectively. The needles disposal enables an uniform bubble distribution along the column which enhances the suspension of low density solids. A concave perspex cylindrical piece, formed by small cones involving each needle, was placed at the column bottom to allow solids circulation in this section, avoiding solids deposition. 


\subsection{Mass transfer experiments}

Oxygen mass transfer experiments were performed in two and three-phase systems at different temperatures, $T\left(20,25,30,35^{\circ} \mathrm{C}\right)$. Air and water were used as gas and liquid phases,respectively. Polyvinyl chloride (PVC) beads of two different sizes (210 and $549 \mu \mathrm{m})$ with a density $\left(\rho_{s}\right)$ of $1350 \mathrm{~kg} / \mathrm{m}^{3}$, and expandable polystyrene (EPS) (with mean diameter, $d_{p}$, of $591 \mu \mathrm{m}$, and a density of $\rho_{s}=1040-1050 \mathrm{~kg} / \mathrm{m}^{3}$ ) were used as solid phase. The experiments were performed for several superficial gas velocities, $u_{G}$ (up to $7.2 \mathrm{~mm} / \mathrm{s}$ ), and different solid volume fraction, $\varepsilon_{s}$ (up to $5 \%$ ). The clear liquid height was $h_{0}=0.32 \mathrm{~m}$ for all experiments (no liquid throughput). Table 1 presents a summary of the experimental conditions, for the different phases, used in the present work.

Initially the liquid is deoxygenated by bubbling nitrogen. When the dissolved oxygen concentration is practically zero, humidified air is fed into the column. At this moment the oxygen transfer process from bubbles to the liquid begins and continues until oxygen concentration in the liquid reaches the saturation. Dissolved oxygen concentration values were measured on-line using an $\mathrm{O}_{2}$ electrode (CellOx 325, WTW), located $0.1 \mathrm{~m}$ from the gas sparger, and recorded directly in a PC, through a data acquisition board. By this way, the dissolved oxygen concentration variation with time, $t$, is obtained, and $k_{L} a$ can be calculated according to the following procedure.

The mass balance for oxygen in the liquid is written as:

$\frac{d C}{d t}=k_{L} a\left(C^{*}-C\right)$

where $C^{*}$ and $C$ are, respectively, the oxygen solubility and oxygen concentration in the liquid. Assuming the liquid phase homogeneous and $C_{0}$ the oxygen concentration at $t=0$, the integration of the previous equation leads to:

$\ln \left(C^{*}-C\right)=\ln \left(C^{*}-C_{0}\right)-k_{L} a \cdot t$.

The volumetric mass transfer coefficient can now be determined by plotting $\ln \left(C^{*}-C\right)$ against time $(t)$. The experimental results are reproducible with an average relative error of $5 \%$.

The solubility of oxygen in water $\left(C^{*}\right)$ was taken experimentally for each run and the slope was determined using the statistical method Test $F$. This method consists in determining the optimum number of points $\left(n_{p}\right)$ for a linear regression of the experimental data.

\subsection{Visualization of bubble-particle interaction}

In order to understand the effect of physical and chemical properties of the solids on mass transfer process the experimental set-up presented in Fig. 2 was used. In this set-up the bubble/particle interaction in three phase systems is studied at different conditions. The images were grabbed with a black and white high speed digital video camera, that was connected to a PC. Sets of images were recorded for several superficial gas velocities and constant solid loading (3 vol.\%) of PVC and EPS.

\section{Results and discussion}

\subsection{Mass transfer experiments}

\subsubsection{Air/water}

The most common experiments on mass transfer available in the literature are done at ambient conditions. In Table 2 several important correlations to predict the mass transfer coefficient in bubble columns are presented. The evaluation of its applicability in air/water system at different temperatures was done for several experimental conditions.

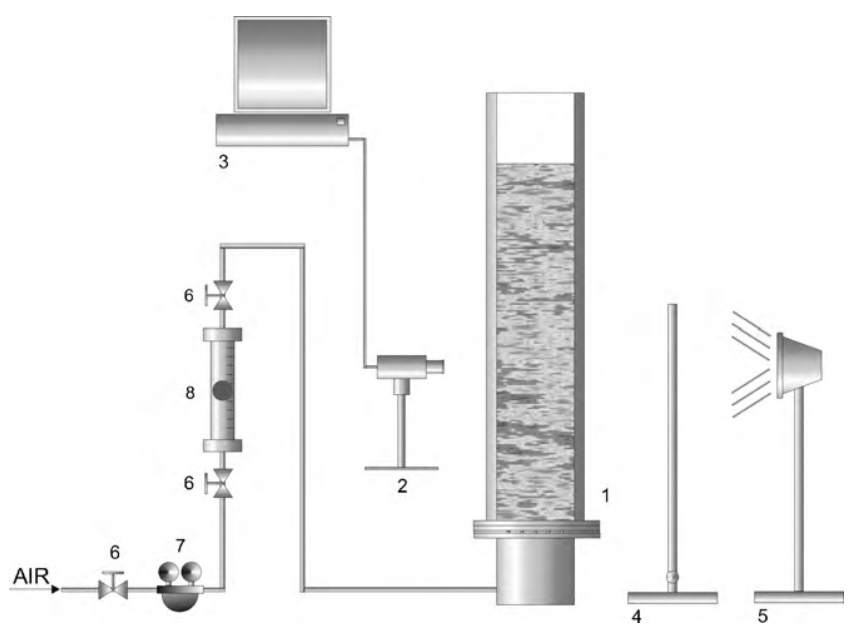

Fig. 2. Experimental set-up for visualization measurements (1: bubble column (20 mm of internal diameter), 2: digital camera, 3: PC, 4: diffuser glass, 5: halogen lamp, 6: on/off valve, 7: pressure reducer, and 8: rotameter).

In Fig. 3 the experimental results, obtained in present work at $25^{\circ} \mathrm{C}$, are compared with some of the correlations presented in Table 2. These correlations were chosen taking into account the ones that include temperature dependent variables (e.g. diffusivity, viscosity, interfacial tension, etc.).

As one can see, the correlations underestimate the experimental values, probably due to differences in the experimental conditions, mainly in superficial gas velocity range and bubble column diameter. Kawase et al. [24], Hikita et al. [25] and Koide et al. [26] works present superficial gas velocities above $0.02 \mathrm{~m} / \mathrm{s}$, while Akita and Yoshida [27] worked in the range of $0.003-0.4 \mathrm{~m} / \mathrm{s}$. In what concerns the column diameter, all these authors used $D_{T}$ above $0.1 \mathrm{~m}$. Overestimation is obtained using the Ozturk et al. [28] correlation (not presented in Fig. 3) probably as a consequence of system properties as mass transfer studies were done mainly in organic liquids. The results are well fitted by a correlation in the form of $k_{l} a=m u_{G}^{n}$, with the parameters $m$ and $n$ equal to 2.81 and 1.02 , respectively. The same type of correlation can be found in the literature, as for example in Deckwer et al. work [29], however the individual parameters are only valid for a specific situation.

In order to understand the effect of $a$ and $k_{L}$ on mass transfer process these parameters were studied individually. The first parameter $a$, was studied based on literature results obtained for

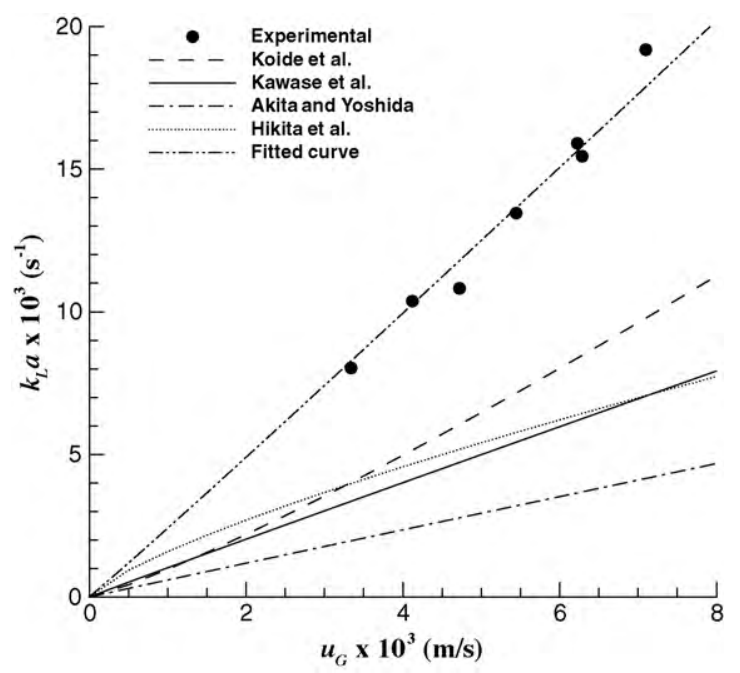

Fig. 3. Dependence of $k_{L} a$ on superficial gas velocity for air/water system at $25^{\circ} \mathrm{C}$. 
Table 1

Experimental conditions used in this work.

\begin{tabular}{|c|c|c|c|c|c|c|c|}
\hline \multirow{2}{*}{$\begin{array}{l}\text { Liquid phase } \\
T\left({ }^{\circ} \mathrm{C}\right)\end{array}$} & \multirow{2}{*}{$\begin{array}{l}\text { Gas phase } \\
u_{G}\left(\times 10^{3} \mathrm{~m} \mathrm{~s}^{-1}\right)\end{array}$} & \multicolumn{6}{|c|}{ Solid phase } \\
\hline & & Type & $d_{p}(\mu \mathrm{m})$ & $\varepsilon_{S}(\%)$ & $\rho_{s}\left(\mathrm{~g} \mathrm{~cm}^{-3}\right)$ & Surface property & Contact angle $\left({ }^{\circ}\right)$ \\
\hline $20 ; 25 ; 30 ; 35$ & Up to 7.2 & - & - & - & - & - & - \\
\hline $25 ; 30 ; 35$ & Up to 7.2 & PVC & 549 & $1 ; 2 ; 4$ & 1.35 & Hydrophobic & 103 \\
\hline $25 ; 30$ & Up to 7.2 & PVC & 210 & $1 ; 2 ; 4$ & 1.35 & Hydrophobic & 103 \\
\hline $25 ; 30 ; 35$ & Up to 7.2 & EPS & 591 & $1 ; 5$ & 1.05 & Hydrophobic & 98 \\
\hline
\end{tabular}

Table 2

Mass tranfer coefficient correlations for gas-liquid bubble columns

\begin{tabular}{|c|c|c|}
\hline Research group & Correlation & Reference \\
\hline Ozturk et al. [28] & $\frac{k_{L} a d_{b}^{2}}{D_{L}}=0.62\left(\frac{\mu_{l}}{\rho_{l} D_{L}}\right)^{0.5}\left(\frac{g \rho_{l} d_{b}^{2}}{\sigma}\right)^{0.33}\left(\frac{g \rho_{l}^{2} d_{b}^{3}}{\mu_{l}^{2}}\right)\left(\frac{u_{G}}{\sqrt{g d_{b}}}\right)^{0.68}\left(\frac{\rho g}{\rho_{l}}\right)^{0.04}$ & [3] \\
\hline Akita and Yoshida [27] & $\frac{k_{L} a D_{T}^{2}}{D_{L}}=0.6\left(\frac{\mu_{l}}{\rho_{l} D_{L}}\right)^{0.5}\left(\frac{g \rho_{l} D_{T}^{2}}{\sigma}\right)^{0.62}\left(\frac{g \rho_{l}^{2} D_{T}^{3}}{\mu_{l}^{2}}\right)^{0.31} \varepsilon_{G}^{1.1}$ & {$[46]$} \\
\hline Shah et al. [4] & $k_{L} a=0.467 u_{G}^{0.82}$ & {$[46]$} \\
\hline Kawase et al. [24] & $\frac{k_{L} a D_{T}^{2}}{D_{L}}=0.452\left(\frac{\mu_{l}}{\rho_{l} D_{L}}\right)^{1 / 2}\left(\frac{\rho_{l} D_{T}^{2} u_{G}}{\mu_{l}}\right)^{3 / 4}\left(\frac{g D_{T}^{2} \rho_{l}}{\sigma}\right)^{3 / 5}\left(\frac{u_{G}^{2}}{D_{T} g}\right)^{7 / 60}$ & [46] \\
\hline Hikita et al. [25] & $\frac{k_{L} a u_{G}}{g}=14.9\left(\frac{u_{G} \mu_{l}}{\sigma}\right)^{1.76}\left(\frac{\mu_{l}^{4} g}{\rho_{l} \sigma^{3}}\right)^{-0.248}\left(\frac{\mu_{g}}{\mu_{l}}\right)^{0.243}\left(\frac{\mu_{l}}{\rho_{l} D_{A B}}\right)^{-0.604}$ & [47] \\
\hline Kang et al. [48] & $k_{L} a=k \times 10^{-3.08}\left(\frac{D_{T} u_{G} \rho_{g}}{\mu_{l}}\right)^{0.254}$ & [47] \\
\hline Schumpe and Grumd [49] & $k_{L} a=k u_{G}^{0.82} \mu^{*^{-0.39}}, \quad k=0.063$ or $k=0.042$ & [47] \\
\hline \multirow[t]{2}{*}{ Koide et al. [26] } & $\frac{k_{L} a \sigma}{\rho^{\prime} D^{\prime} \sigma}=\frac{2.11\left(\mu_{l} / \rho_{l} D_{L}\right)^{0.5}\left(g \mu_{l}^{4} / \rho_{l} \sigma_{l}^{3}\right)^{-0.159} \varepsilon_{G}^{1.18}}{0.486}$ & \multirow[t]{2}{*}{ [47] } \\
\hline & $\rho_{l} D_{l}^{\prime g} \quad 1+1.47 \times 10^{4}\left(C_{S} / \rho_{S}\right)^{0.612}\left(U_{t \infty} / \sqrt{D_{c} g}\right)^{0.486}\left(D_{c} u_{G} \rho_{l} / \mu_{l}\right)^{-0.345}$ & \\
\hline
\end{tabular}

the same column used in present work. Mena et al. [13] obtained experimental values of $a$ using image analysis technique associated with Wesselingh and Bollen model [30]. According to the authors the specific interfacial area was calculated using the following equation:

$a=\frac{N_{b} A_{\text {sup }}}{V_{L}}$

where $N_{b}$ is the number of bubbles in the column at a certain instant, $A_{\text {sup }}$ is the mean superficial area of the bubbles and $V_{L}$ is the liquid volume. The bubble superficial area was determined by image analysis technique. The rise velocity of bubbles was calculated from Wesselingh and Bollen [30] and used to determine $N_{b}$. For the size range of the bubbles, classified as elongated or flattened spheroids, the rise velocity is nearly constant. As example, for $u_{G}=2 \mathrm{~mm} / \mathrm{s}, d_{b}=3.5 \mathrm{~mm}$ and the rise velocity of bubbles takes the value of $0.241 \mathrm{~m} / \mathrm{s}$. The results obtained by Mena et al. [13] at $20^{\circ} \mathrm{C}$ for air-water system at different superficial velocities are presented in Fig. 4. In this figure, some literature correlations are also present.

As expected $[9,11,21]$, interfacial area increases with superficial gas velocity. This happens even as the bubbles become larger, since the number of bubbles formed increases, therefore increasing the total superficial area. Comparing with literature correlations [9,31], experimental data shows good agreement with the Quicker et al. [9] correlation (developed for non-coalescing sodium sulfite solution with hydrophilic particles):

$a=651 u_{G}^{0.87} \mu^{*^{-0.24}}$

where $\mu^{*}$ is the effective viscosity of the particle-fluid mixture calculated based on Einstein expression [32] which linearly relates the effective viscosity and the particles concentration as follows:

$\frac{\mu^{*}}{\mu_{l}}=1+2.5 f$ where $\mu_{l}$ is the viscosity of the fluid and $f$ the volumetric concentration of the particles. This expression has a particular interest on three phase systems where the volumetric concentration of the particles has influence on the viscosity of the system and, consequently, on the interfacial area.

So, with $a$ previously determined, $k_{L}$ can now be calculated from the $k_{L} a$ values. In Fig. 5 , the experimental $k_{L}$ values obtained for air/water system are compared with values determined from the literature correlations.

As expected, based on previous comparison (Fig. 3), a poor agreement was obtained for the most of the correlations. Aiming

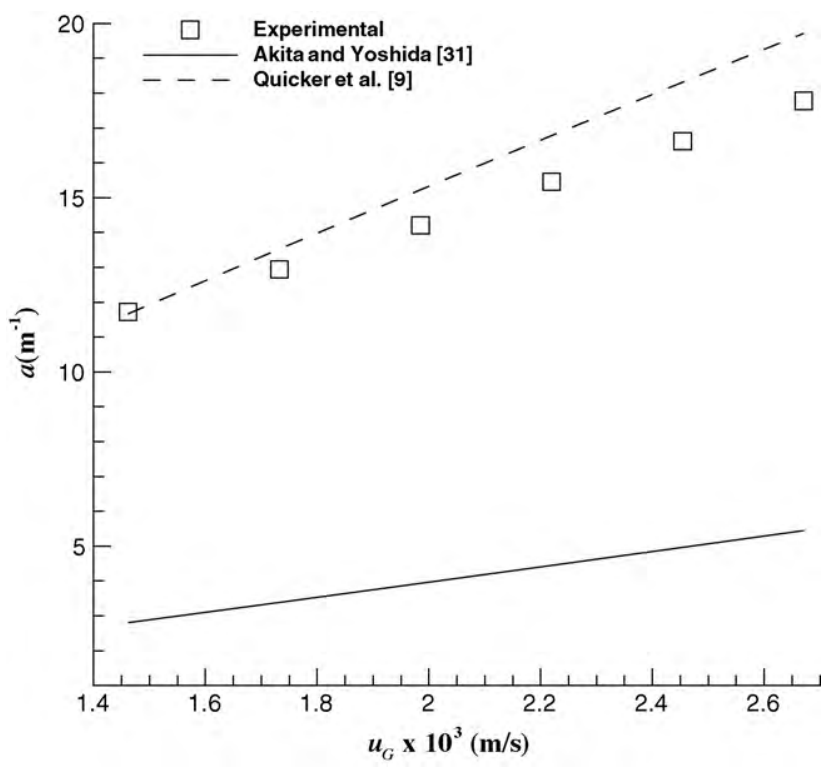

Fig. 4. Experimental gas-liquid interfacial area and some of the literature correlations for air/water system [38]. 


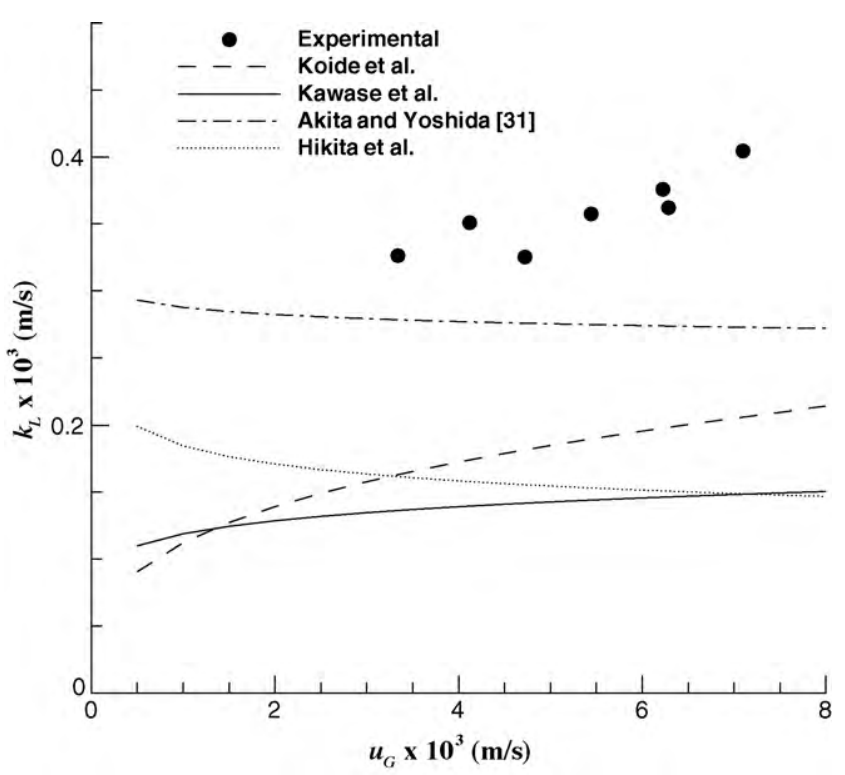

Fig. 5. Experimental liquid side mass transfer coefficient and literature correlations for air/water system at $25^{\circ} \mathrm{C}$.

to obtain a $k_{L}$ correlation describing the experimental results, the conclusion presented in Dudley study [33] was followed. Dudley recommends the Kawase's correlation for general use. However, in the present study this correlation does not fit the experimental data and, as a consequence, the Kawase's correlation was used as follows:

$k_{L}=f^{\prime} \times 2 \sqrt{\frac{D_{L}}{\pi} \sqrt{\frac{u_{G} g}{\mu_{l}}}}$

where $f$ is a correction factor, which was determined by the least squares method and takes the value $2.59, D_{L}$ is the diffusivity of gas in the liquid and $\mu_{l}$ the viscosity of liquid phase, both temperature dependents. The change of $D_{L}$ with temperature was calculated according to Han and Bartels correlation [34], while $\mu_{l}$ was taken from literature [35]. Therefore, the correlation that will be applied in present work, for the two phase system, takes the following form:

$k_{L} a=5.18 \sqrt{\frac{D_{L}}{\pi} \sqrt{\frac{u_{G} g}{\mu_{l}}}} 651 u_{G}^{0.87} \mu^{*^{-0.24}}$

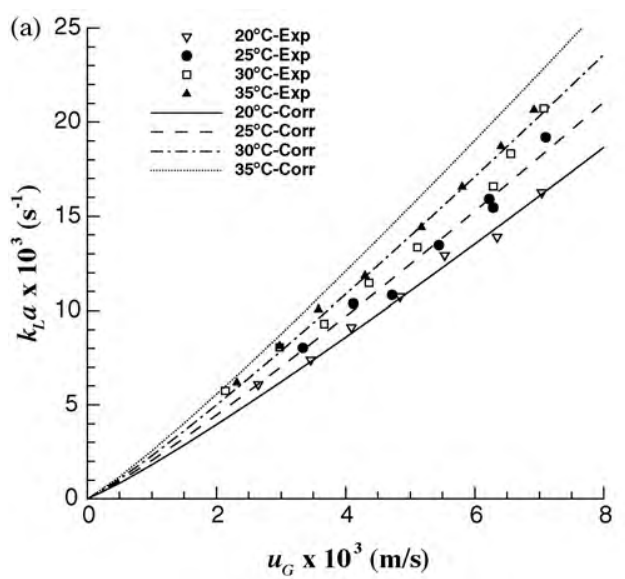

Table 3

Deviations obtained from the application of Eq. (7) for two phase systems.

\begin{tabular}{lrrlr}
\hline$T\left({ }^{\circ} \mathrm{C}\right)$ & $M_{\text {error }}$ & $A_{\text {error }}$ & & \multicolumn{2}{l}{ Global } & \\
\cline { 5 - 5 } & & & $M_{\text {error }}$ & $A_{\text {error }}$ \\
\hline 20 & 11.3 & 3.7 & & \\
25 & 7.8 & 3.2 & 9.9 & 5.1 \\
30 & 8.6 & 5.0 & & \\
35 & 11.9 & 8.7 & & \\
\hline
\end{tabular}

The previous correlation was applied to different temperatures $\left(20,25,30,35^{\circ} \mathrm{C}\right)$ and superficial gas velocities, $u_{G}$, and compared with the experimental results. Fig. 6(a) corroborates the good agreement between experimental and correlated values, which is confirmed by the parity plot presented in Fig. 6(b). The maximum and mean deviations between the experimental and correlated results ( $M_{\text {error }}$ and $A_{\text {error }}$, respectively) at different temperatures are presented in Table 3. Globally, maximum and mean deviations take the values 9.9 and $5.1 \%$, respectively. The highest deviation is observed at $35^{\circ} \mathrm{C}$, probably due to the formation of large bubbles as a result of bubble coalescence. This situation is not predicted by Eq. 7. In spite of this, its application at $35^{\circ} \mathrm{C}$ predicts, in a very satisfactory way, the experimental results.

In this figure, data from Akita and Yoshida correlation [27] at different temperatures are also plotted. As expected (Figs. 4 and 5), the correlation underestimates the experimental values. According to Fig. 5, the difference with Akita and Yoshida data is mainly related with $a$ calculation. These authors predict a mean bubble size two times higher than the one observed in present work. However, it seems that this correlation describes well the temperature variation.

In order to study the effect of the solids properties (size and density) on gas-liquid mass transfer, at different temperatures, several experiments were done using PVC and EPS as solid phase.

\subsubsection{Air/water/polyvinyl chloride (PVC)}

The effect of solid size and loading on the mass transfer coefficient, at different temperatures, is shown in Figs. 7 and 8. The results show that increasing solid size and loading the mass transfer coefficient decreases. Dhanuka and Stepanek [36] and Zheng et al. [37] mentioned a similar influence of particle size on $k_{L} a$, but an opposite effect was reported by Kim and Kim [21] and Mena [38]. The decrease in $k_{L} a$ observed at higher solid concentrations could be due to a greater number of bubble collisions resulting in increased coalescence, and hence an increase in bubble size and a decrease in the interfacial area [39]. It seems, also, that temperature does not affect significantly the solids influence on mass transfer.

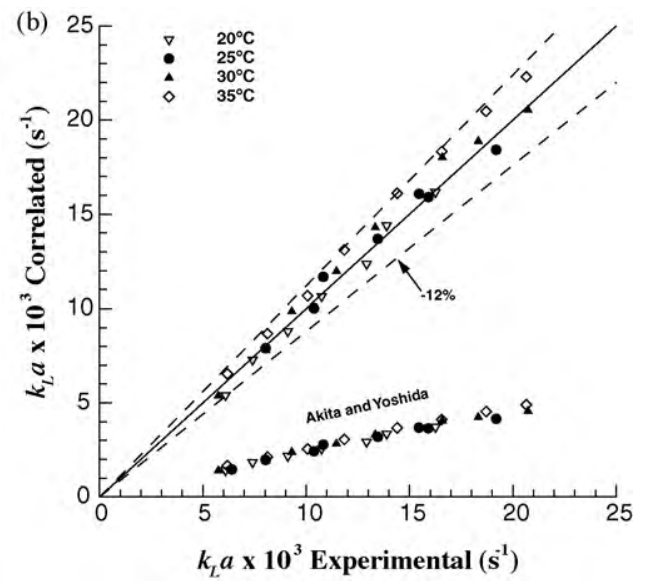

Fig. 6. Dependence of $k_{L} a$ on superficial gas velocity for air/water system at different temperatures. 

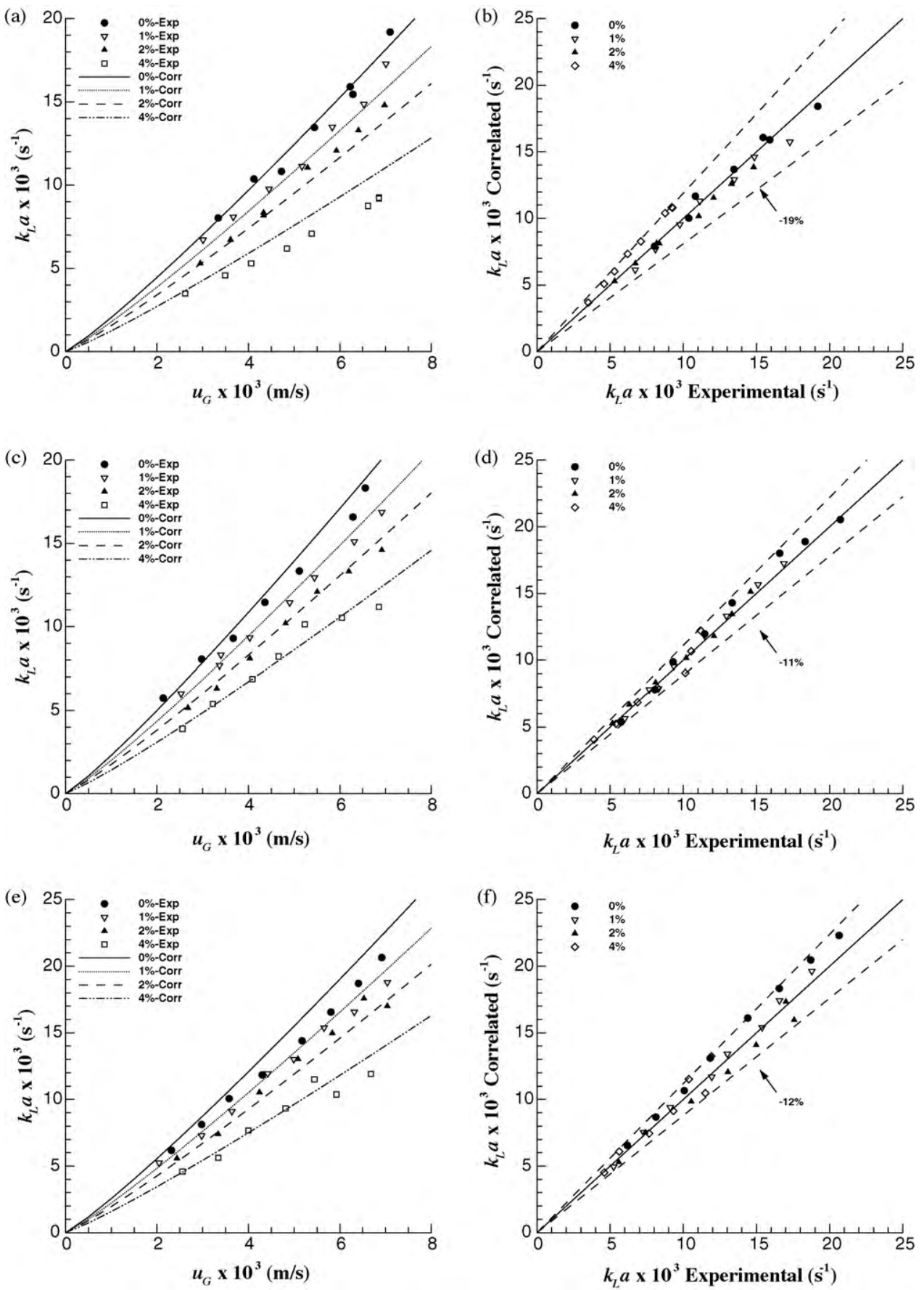

Fig. 7. Effect of PVC particle $\left(d_{p}=549 \mu \mathrm{m}\right)$ loading on mass transfer coefficient at $25^{\circ} \mathrm{C}(\mathrm{a}, \mathrm{b}), 30^{\circ} \mathrm{C}(\mathrm{c}, \mathrm{d})$ and $35^{\circ} \mathrm{C}(\mathrm{e}, \mathrm{f})$.

The impact of changing temperature on these systems is given by the temperature influence on the physical properties of the liquid and gas. An increase in temperature reduces, significantly, both liquid viscosity and surface tension, resulting in the formation of small and stable bubbles, by one way, and increases the probability of coalescence, by other way $[2,40]$. It is this duality that alters the interfacial area and has a significant impact on the mass transfer process. Deckwer et al. [41] and Grover at al. [42] found that the gas holdup decreases with increasing temperature. On the contrary, Lin et al. [43] report that elevating temperature increases gas holdup.

The physical properties change with the temperature has also a great influence on $k_{L}$. Viscosity decrease leads to a decrease in the thickness of the stagnant film at gas/liquid interface and, also to an increase in diffusion coefficient. Both effects conduct to an increase in mass transfer coefficient.

In a previous work, Mena et al. [13], it was concluded that the shape of the bubbles is influenced by superficial gas velocity, concentration and size of solids (in this case, calcium alginate beads with a mean diameter of 1.2 and $2.1 \mathrm{~mm}$ ). The solids make the bubbles more rounded, the effect being more pronounced for the higher solids loading and for the smaller particles. The influence on bubble size (increasing it) and consequently on interfacial area, $a$ (decreasing it), is clear for the smaller particles and high concentrations, while for the larger particles and smaller particles at low concentration the effect is negligible. By the other hand, the effect of the solids on $k_{L}$ is more pronounced (decreasing it) for the smaller particles at higher concentration. So, for smaller parti- 

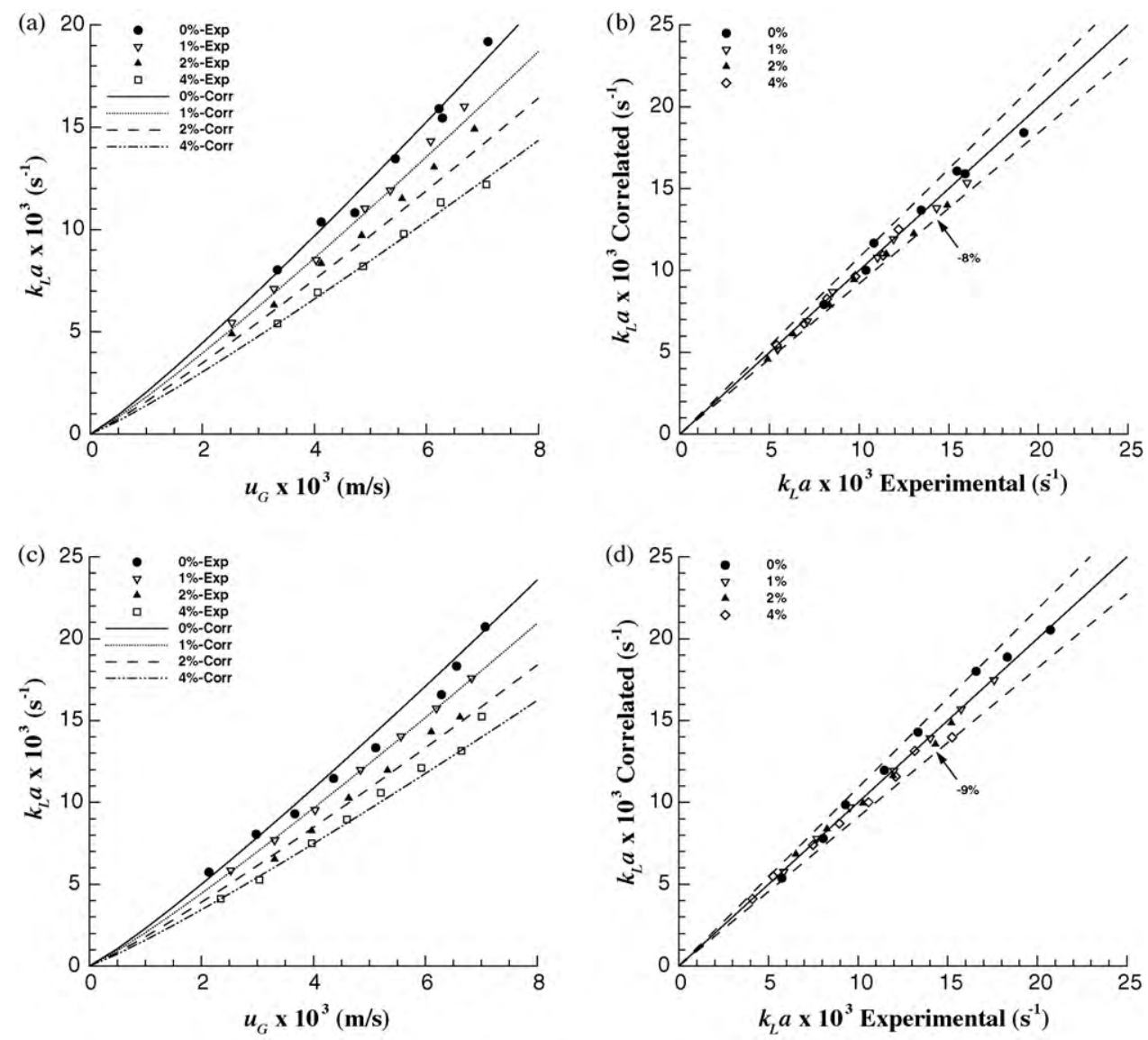

Fig. 8. Effect of PVC particle $\left(d_{p}=210 \mu \mathrm{m}\right)$ loading on mass transfer coefficient at $25^{\circ} \mathrm{C}(\mathrm{a}, \mathrm{b})$ and $30^{\circ} \mathrm{C}(\mathrm{c}, \mathrm{d})$.

cles and low concentration the effect of solids would be mainly on $k_{L}$. In the present work, the quantification of the two components of $k_{L} a$ was not done. So, based on image analysis tests (the shape and size evolution of bubbles in actual circumstances are similar) and on the findings of the previous work about the influence of the size and concentration of solids, one decided, as Eq. (7) applied to three phase systems experimental data gave unsatisfactory results, to add two terms to this equation, taking into account the effects of the size and concentration of solids. The correlation obtained takes the following form:

$k_{L} a=5.18 \sqrt{\frac{D_{L}}{\pi} \sqrt{\frac{u_{G} g}{\mu_{L}}}} 651 u_{G}^{0.87} \mu^{*^{-0.24}}\left(1-d_{p}\right)^{0.036}\left(1-\varepsilon_{s}\right)^{9.66}$

This correlation was applied to different experimental conditions and compared with experimental results. Figs. 7 and 8 corroborate the good agreement between experimental and correlated values. It seems that Eq. (8) predicts, in a very satisfactory way, the experimental results. The maximum and mean deviations between the experimental and correlated results at different temperatures are presented in Table 4. Globally, the maximum deviations take the values of 5.1 and $9.4 \%$, for the sizes 210 and $549 \mu \mathrm{m}$, respectively and the mean deviations take the values 2.9 and $5.4 \%$, for the sizes 210 and $549 \mu \mathrm{m}$, respectively.

\subsubsection{Air/water/expandable polystyrene (EPS)}

Many studies have been done regarding the effect of solid particles on gas-liquid system. Some systems show an enhanced $k_{L} a$ and others a decrease relative to systems without particles. It is clear, however, that the effect of the particles on the system is a function of particle properties, bubble column dimension, type of sparger and operation conditions. Such particle properties include density, size, hydrophobicity, and concentration of particles [44]. In the present section we intend to study the solid density effect on mass transfer. For that the system air/water/expandable polystyrene (EPS) beads was used, and the results compared with the results of the previous section. The applicability of Eq. (8) was also tested.

In Fig. 9, the solid loading effect on the mass transfer coefficient, at different temperatures, is presented.

It can be observed that the influence of $u_{G}$ on $k_{L} a$ decreases as the solid loading increases. It is possible to identify two regions regarding the influence of $u_{G}$ on $k_{L} a$ at the different temperatures. For values of $u_{G} \leq 4 \times 10^{-3} \mathrm{~m} / \mathrm{s}$ the volumetric mass transfer coefficient increases with the superficial gas velocity and decreases with the solid concentration. The same behaviour was observed in the previous section. On the other hand, for $u_{G}>4 \times 10^{-3} \mathrm{~m} / \mathrm{s}$ the volumetric mass transfer coefficient slightly increases with superficial gas velocity in the experiments containing solids, being this effect reduced as the solid loading increases. This evidence suggests that the expected number of bubbles due to $u_{G}$ increase is attenuated by the formation of large bubbles, therefore, $a$ has a practically constant value with $u_{G}$ increase. This behaviour was not observed in the system containing PVC particles at similar particle size. So, the previous observation can be attributed to the difference of the physical property of the particles, e.g. density.

The application of Eq. (8) to the present system was done and a poor agreement is observed (Fig. 9). This may due to the bubble coalescence or other phenomenon that reduces the interfacial area. The maximum and mean absolute deviations between experimental and correlated results are 32 and 16\% (Table 4). 
Table 4

Deviations obtained from the application of Eq. (8) for three phase systems.

\begin{tabular}{|c|c|c|c|c|c|c|c|c|c|c|}
\hline \multicolumn{3}{|l|}{ Solid } & \multicolumn{2}{|l|}{$25^{\circ} \mathrm{C}$} & \multicolumn{2}{|l|}{$30^{\circ} \mathrm{C}$} & \multicolumn{2}{|l|}{$35^{\circ} \mathrm{C}$} & \multicolumn{2}{|c|}{ Global } \\
\hline Type & $d_{p}(\mu \mathrm{m})$ & $\varepsilon_{s}(\%)$ & $M_{\text {error }}$ & $A_{\text {error }}$ & $M_{\text {error }}$ & $A_{\text {error }}$ & $M_{\text {error }}$ & $A_{\text {error }}$ & $M_{\text {error }}$ & $A_{\text {error }}$ \\
\hline \multirow[t]{6}{*}{ PVC } & 549 & 1 & 8.9 & 4.6 & 5.9 & 3.3 & 5.5 & 3.4 & & \\
\hline & & 2 & 7.9 & 3.6 & 6.0 & 2.7 & 9.1 & 5.4 & 9.4 & 5.4 \\
\hline & & 4 & 18.8 & 14.8 & 10.6 & 4.4 & 11.2 & 6.5 & & \\
\hline & 210 & 1 & 5.1 & 2.9 & 1.8 & 1.0 & - & - & & \\
\hline & & 2 & 6.7 & 5.0 & 5.2 & 3.3 & - & - & 5.1 & 2.9 \\
\hline & & 4 & 3.6 & 1.9 & 8.3 & 3.3 & - & - & & \\
\hline \multirow[t]{2}{*}{ EPS } & 591 & 1 & 17.8 & 7.1 & 41.0 & 17.6 & 47.8 & 24.3 & 31.8 & 15.7 \\
\hline & & 5 & 27.9 & 13.8 & 27.2 & 16.4 & 28.9 & 15.2 & & \\
\hline
\end{tabular}
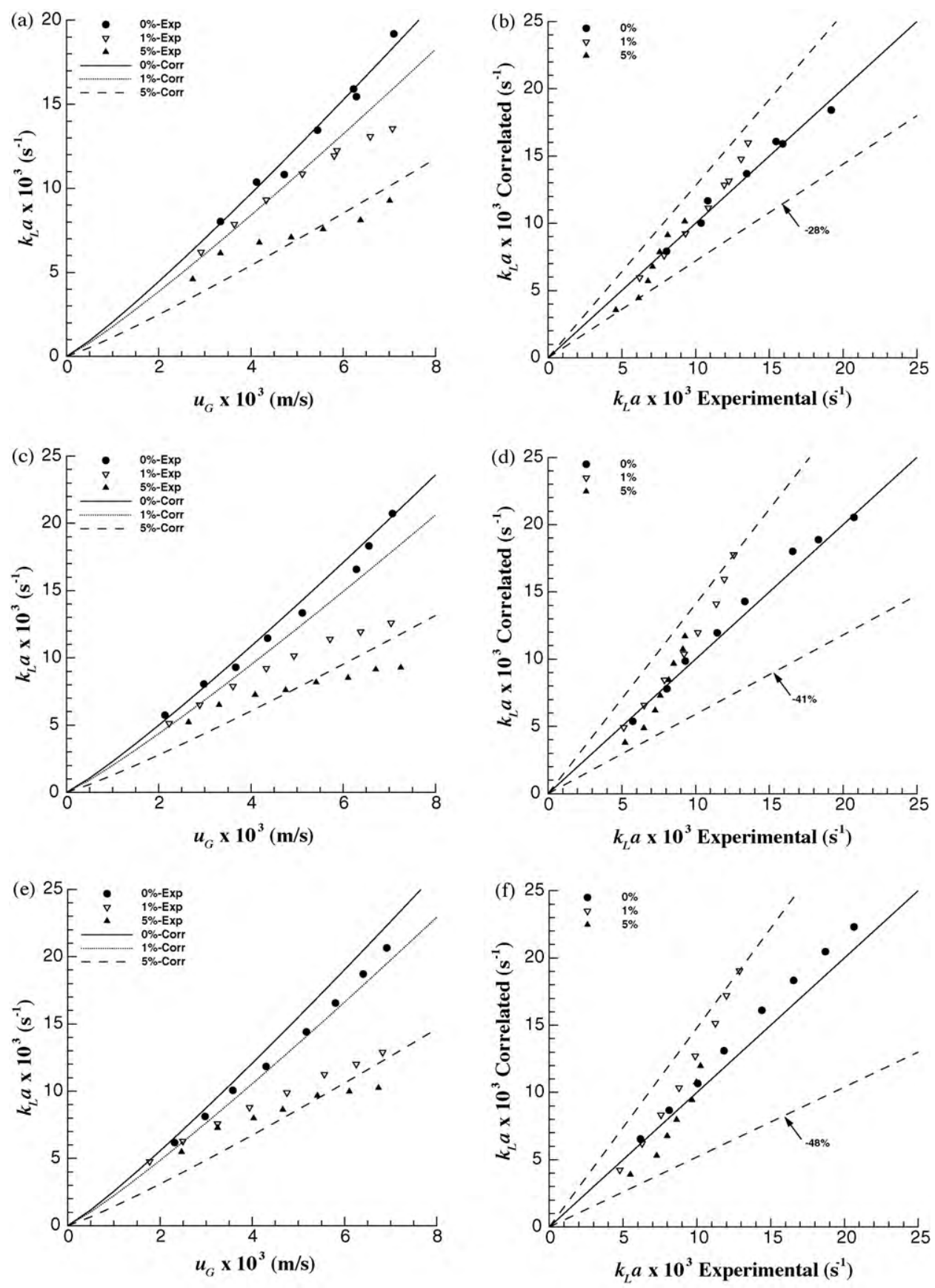

Fig. 9. Effect of EPS particle $\left(d_{p}=591.2 \mu \mathrm{m}\right)$ loading on mass transfer coefficient at $25^{\circ} \mathrm{C}(\mathrm{a}, \mathrm{b}), 30^{\circ} \mathrm{C}(\mathrm{c}, \mathrm{d})$ and $35^{\circ} \mathrm{C}(\mathrm{e}, \mathrm{f})$. 
(a)

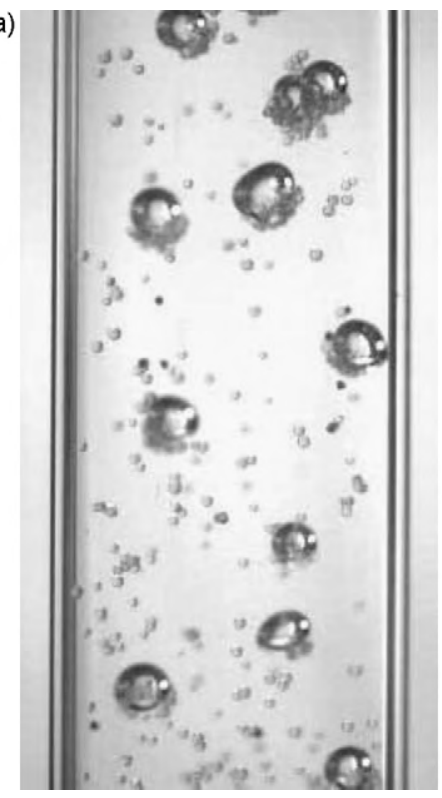

(b)

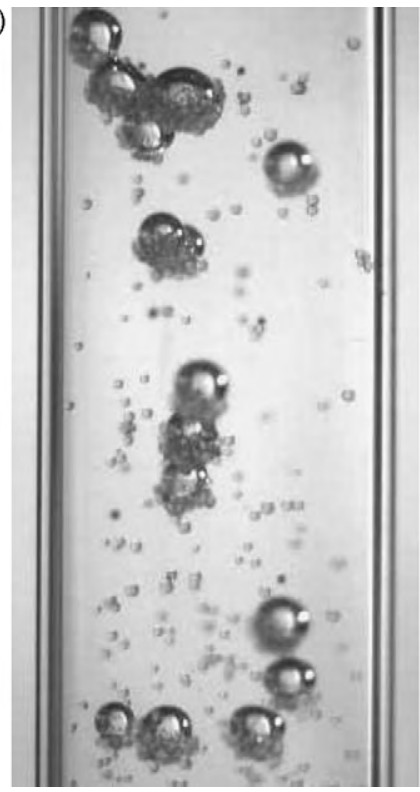

(c)

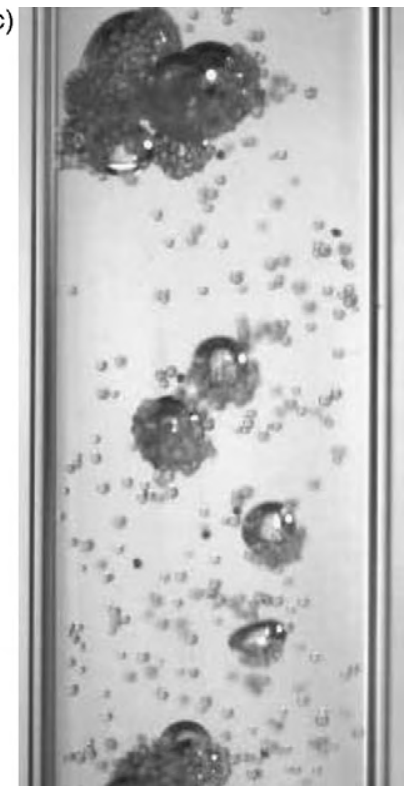

Fig. 10. Bubble contamination and coalescence in the presence of 3 vol. $\%$ of EPS at $25^{\circ} \mathrm{C}$ and: (a) $u_{G}=3 \times 10^{3} \mathrm{~m} / \mathrm{s} ;(\mathrm{b}) u_{G}=5 \times 10^{-3} \mathrm{~m} / \mathrm{s} ;$ and $(\mathrm{c}) u_{G}=7 \times 10^{-3} \mathrm{~m} / \mathrm{s}$.

\subsection{Visualization of bubble-particle interaction}

Auxiliary visualization experiments were done in order to investigate the three phase systems in more detail, namely the pattern of the bubble/particle interactions, to obtain arguments to support some possible mechanisms responsible for the observed trends at air/water/EPS system. It is usually considered that the bubble coalescence is responsible for the destabilizing effect of the solid phase. According to their physical and chemical properties, solids can suppress and promote the coalescence.

Fig. 10 shows different images obtained at different $u_{G}$ for the system containing EPS particles.

As one can see the particles have a great affinity to the bubble surface, reducing, by this way, the interfacial area and $k_{L} a$, and increasing the contact time between bubble and liquid. Increasing $u_{G}$ the number of bubbles increases and it is expected that $a$ increases also. However, this behaviour was not observed. With $u_{G}$ increase, it was verified that the coalescence of bubbles increases and the physical attraction of the particles contributes for that. At higher superficial gas velocities (Fig. 10(c)) the bubbles are, mostly, big bubbles surrounded by particles. This particle affinity to the bubbles is due not only to its surface properties but also to its low density (similar to the water density) that facilitates the dragging of particles by the bubbles. The same type of experiments was also done in the presence of PVC particles, but the affinity of the solid particles to the bubble was not observed. These results can explain the different behaviours of $k_{L}$ a curves obtained in previous sections in the presence of different solid particles. Further, they point out the importance of the study of phase interaction in the knowledge of mass transfer process in bubble columns. These conclusions corroborate the Lefebvre and Guy [45] conclusion. According to the authors, the not good understanding of bubble columns is linked to the insufficient study of the interaction between phases.

\section{Conclusions}

The gas-liquid mass transfer process was investigated in a three-phase bubble column at different temperatures. The main purpose was to analyze the effect of certain solid properties on the gas/liquid mass transfer at different temperatures. The solid characteristics under study were the solid type, loading and size. It can be concluded that the solid size and loading have a negative effect on $k_{L} a$, being the type of this effect not significantly changed by the temperature. In what concerns the solid type influence, it was observed that solid density has a strong impact on $k_{L} a$. A significant reduction on mass transfer occurs in the presence of EPS particles due to its low density and high affinity to the bubble interface.

An empirical correlation for $k_{L} a$ dependence on the experimental variables was developed. The mean deviation obtained was, approximately, 5\%, a value similar to the experimental error. However, the applicability of this equation is limited to the systems where the surface contamination of the bubbles is negligible. The obtained experimental results indicate that further investigation in bubble/particle and bubble/bubble interactions is needed for a correct understanding of solid properties (physical and chemical) influence on mass transfer and hydrodynamic in bubble columns.

\section{Acknowledgements}

This work was supported by Fundação para a Ciência e Tecnologia under program contract number SFRH/BPD/45637/2008.

\section{References}

[1] S. Degaleesan, M. Dudukovic, Y. Pan, Experimental study of gas-induced liquidflow structures in bubble columns, AIChE J. 47 (2001) 1913-1931.

[2] R. Schafer, C. Merten, G. Eigenberger, Bubble size distributions in a bubble column reactor under industrial conditions, Exp. Therm. Fluid Sci. 26 (2002) 595-604.

[3] N. Kantarci, F. Borak, K.O. Ulgen, Bubble column reactors, Process Biochem. 40 (2005) 2263-2283.

[4] Y.T. Shah, B.G. Kelkar, S.P. Godbole, W.D. Deckwer, Design parameters estimations for bubble column reactors, AIChE J. 28 (1982) 353-379.

[5] W. Yang, J. Wang, T. Wang, Y. Jin, Experimental study on gas-liquid interfacial area and mass transfer coefficient in three-phase circulating fluidized beds, Chem. Eng. J. 84 (2001) 485-490.

[6] O. Ozkan, A. Calimli, R. Berber, H. Oguz, Effect of inert solid particles at low concentrations on gas-liquid mass transfer in mechanically agitated reactors, Chem. Eng. Sci. 55 (2000) 2737-2740.

[7] E. Sada, H. Kumazawa, C. Lee, N. Fujiwara, Gas-liquid mass transfer characteristics in a bubble column with suspended sparingly soluble fine particles, Ind. Eng. Chem. Process Des. Dev. 24 (1985) 255-261.

[8] E. Alper, W.D. Deckwer, P.V. Danckwerts, Comparison of effective interfacial areas with the actual contact area for gas absortion in a stirred cell, Chem. Eng. Sci. 35 (1980) 1263-1268.

[9] G. Quicker, A. Schumpe, W.D. Deckwer, Gas-liquid interfacial areas in a bubble column with suspended solids, Chem. Eng. Sci. 39 (1984) 179-183. 
[10] F. Camacho, E. Molina, F. Valdés, J.M. Andujar, Influence of operating and physical variables on interfacial area determination, AIChE J. 37 (1991) 1196-1204.

[11] G. Vázquez, M.A. Cancela, C. Reverol, E. Alvarez, J.M. Navaza, Determination of interfacial areas in a bubble column by different chemical methods, Ind. Eng. Chem. Res. 39 (2000) 2541-2547.

[12] G. Vázquez, M.A. Cancela, C. Riverol, E. Alvarez, J.M. Navaza, Application of the dankwerts method in a bubble column. Effect of surfactants on mass transfer coefficient and interfacial area, Chem. Eng. J. 78 (2000) 13-19.

[13] P.C. Mena, M.C. Pons, J.A. Teixeira, F.A. Rocha, Using image analysis in the study of multiphase gas absorption, Chem. Eng. Sci. 60 (2005) 5144-5150.

[14] C. Boyer, A.-M. Duquenne, G. Wild, Measuring techniques in gas-liquid and gas-liquid-solid reactors, Chem. Eng. Sci. 57 (2002) 3185-3215.

[15] S.L. Kiambi, A.M. Duquenne, A. Bascoul, H. Delmas, Measurements of local interfacial area: application of bi-optical fibre technique, Chem. Eng. Sci. 56 (2001) 6447-6453.

[16] T. Zhang, J. Wang, T. Wang, J. Lin, Y. Jin, Effect of internal on the hydrodynamics in external-loop airlift reactors, Chem. Eng. Process. 44 (2005) 81-87.

[17] P. Mena, F. Rocha, J. Teixeira, P. Sechet, A. Cartellier, Measurement of gas phase characteristics using amonofibre optical probe in a three-phase flow, Chem. Eng. Sci. 63 (2008) 4100-4115.

[18] J. Zahradnik, L. Drapal, F. Kastánek, J. Reznickova, Hydrodynamic and mass transfer characteristics of sectionalized aerated slurry reactors, Chem. Eng. Process. 31 (1992) 263-272.

[19] H. Li, A. Prakash, Heat tranfer and hydrodynamics in a three-phase slurry bubble column, Ind. Eng. Chem. Res. 36 (1997) 4688-4694.

[20] X. Luo, D.J. Lee, R. Lau, G. Yang, L. Fan, Maximum stable bubble size and gas holdup in high-pressure slurry bubble columns, AIChE J. 45 (1999) 665-685.

[21] J.O. Kim, S.D. Kim, Gas-liquid mass transfer in a three-phase fluidized bed with floating bubble breakers, Can. J. Chem. Eng. 68 (1990) 368-375.

[22] E.W. Randall, C.M. Goodall, P.M. Fairlamb, P.L. Dold, C.T. O'Connor, A method for measuring the sizes of bubbles in two- and three-phase systems, J. Phys. E: Sci. Instrum. 22 (1989) 833-837.

[23] C. Freitas, J.A. Teixeira, Oxygen mass transfer in a high solids loading threephase internal-loop airlift reactor, Chem. Eng. J. 84 (2001) 57-61.

[24] Y. Kawase, B. Halard, M. Moo-Young, Theoretical prediction of volumetric mass transfer coefficients in bubble columns for newtonian and non-newtonian fluids, Chem. Eng. Sci. 42 (1987) 1609-1617.

[25] H. Hikita, S. Asal, H. Kikukawa, T. Zalke, M. Ohue, Heat tranfer coefficient in bubble column, Ind. Eng. Chem. Process Des. Dev. 20 (1981) 540-545.

[26] K. Koide, A. Takazawa, M. Komura, H. Matsunaga, Gas holdup and volumetric liquid-phase mass transfer coefficient in solid-suspended bubble columns, J. Chem. Eng. Jpn. 17 (1984) 459.

[27] K. Akita, F. Yoshida, Gas hold-up and volumetric mass transfer coefficients in bubble columns, Ind. Eng. Chem. Process Des. Dev. 12 (1973) 76-80.

[28] S. Ozturk, A. Schumpe, W. Deckwer, Organic liquids in a bubble column: holdups and mass tranfer coefficients, AIChE J. 33 (1987) 14731480 .
[29] W.D. Deckwer, R. Burckhart, G. Zoll, Mixing and mass transfer in tall bubble columns, Chem. Eng. Sci. 29 (1974) 2177-2188.

[30] J.A. Wesselingh, A.M. Bollen, Single particles, bubbles and drops: their velocities and mass transfer coefficients, Trans. IChemE 77 (1999) 89-96.

[31] K. Akita, F. Yoshida, Bublle size, interfacial area, and liquid-phase mass transfer coefficient in bubble columns, Ind. Eng. Chem. Process Des. Dev. 13 (1974) 84-91.

[32] A. Einstein, A new determination of molecular dimensions, Ann. Phys. 19(1906) 289-306.

[33] J. Dudley, Mass transfer in bubble columns: a comparison of correlations, Water Res. 29 (1995) 1129-1138.

[34] P. Han, D.M. Bartels, Temperature dependence of oxygen diffusion in $\mathrm{H}_{2} \mathrm{O}$ and $\mathrm{D}_{2}$ O, J. Phys. Chem. 100 (1996) 5597-5602.

[35] D.R. Lide (Ed.), CRC Handbook of Chemistry and Physics, 90th ed. (Internet Version), CRC Press/Taylor and Francis, Boca Raton, FL, 2010.

[36] V.R. Dhanuka, J.B. Stepanek, Simultaneous measurement of interfacial area and mass transfer coefficient in three phase fluidized beds, AIChE J. 26 (1980) 1029-1038.

[37] C. Zheng, Z. Chen, Y. Feng, H. Hofmann, Mass transfer in different flow regimes of three-phase fluidized beds, Chem. Eng. Sci. 50 (1995) 1571-1578.

[38] P. Mena, Mass transfer and hydrodynamics in multiphase systems, Ph.D. thesis, Faculdade de Engenharia da Universidade do Porto, 2005.

[39] N.C. Panja, R.D. Phaneswara, Measurement of gas-liquid parameters in a mechanically agitated contactor, Chem. Eng. J. 52 (1993) 121-129.

[40] A.A. Kulkarni, J.B. Joshi, Bubble formation and bubble rise velocity in gas-liquid systems: a review, Ind. Eng. Chem. Res. 44 (2005) 5873-5931.

[41] W.D. Deckwer, Y. Louisi, A. Zaidi, M. Ralek, Hydrodynamic properties of the fischer-tropsch slurry process, Ind. Eng. Chem. Process Des. Dev. 19 (1980) 699

[42] G.S. Grover, C.V. Rode, R.V. Chaudhari, Effect of temperature on flow regimes and gas hold-up in a bubble column, Can. J. Chem. Eng. 64 (1986) 501

[43] T.J. Lin, K. Tsuchiya, L.S. Fan, Bubble flow characteristics in bubble columns at elevated pressure and temperature, AIChE J. 44 (1998) 545-560.

[44] J.V. Littlejohns, A.J. Daugulis, Oxygen tranfer in a gas-liquid system containing solids of varying oxigen affinity, Chem. Eng. J. 129 (2007) 67-74.

[45] S. Lefebvre, C. Guy, Characterization of bubble column hydrodynamics with local measurements, Chem. Eng. Sci. 54 (1999) 4895-4902.

[46] K. Shimizu, S. Takada, K. Minekawa, Y. Kawase, Phenomenological model for bubble column reactors: prediction of gas hold-ups and volumetric mass transfer coefficients, Chem. Eng. J. 78 (2000) 21-28.

[47] A. Behkish, Z. Men, J.R. Inga, B.I. Morsi, Mass transfer characteristics in a largescale slurry bubble column reactor with organic liquid mixtures, Chem. Eng. Sci. 57 (2002) 3307-3324.

[48] Y. Kang, Y.J. Cho, K.J. Woo, S.D. Kim, Diagnosis of bubble distribution and mass transfer in pressurized bubble columns with viscous liquid medium, Chem. Eng. Sci. 54 (1999) 4887.

[49] A. Schumpe, G. Grund, The gas disengagement technique for studying gas holdup structure in bubble columns, Can. J. Chem. Eng. 64 (1986) 891-896. 